\title{
Bacillaene, a Novel Inhibitor of Procaryotic Protein Synthesis Produced by Bacillus subtilis: \\ Production, Taxonomy, Isolation, Physico-chemical Characterization and Biological Activity
}

\author{
Pramathesh S. Patel ${ }^{\dagger, *}$, Stella Huang ${ }^{\dagger \dagger}$, Susan Fisher ${ }^{\dagger}$, Dolores Pirnik $^{\dagger}$, \\ Carol Aklonis $^{\dagger}$, Loretta Dean ${ }^{\dagger}$, Edward Meyers ${ }^{\dagger}$, \\ Prabhavathi Fernandes ${ }^{\dagger}$ and Friedrich MaYerL $^{\dagger \dagger}$ Princeton, New Jersey
${ }^{\dagger \dagger}$ Department of Analytical Chemistry, Bristol-Myers Squibb Pharmaceutical Research Institute, Wallingford, Conneticut
${ }^{\dagger \dagger \dagger}$ Process and Research Development, Bristol-Myers Squibb Pharmaceutical Research Institute, New Brunswick, New Jersey \\ ${ }^{\dagger}$ Department of Biomolecular Screening, Bristol-Myers Squibb Pharmaceutical Research Institute,
}

(Received for publication April 10, 1995)

\begin{abstract}
Bacillaene, a novel polyene antibiotic, was discovered and isolated from fermentation broths of a strain of Bacillus subtilis. The novel antibiotic has a nominal molecular weight of 580 and an empirical formula of $\mathrm{C}_{35} \mathrm{H}_{48} \mathrm{O}_{7}$. Bacillaene is active against a broad spectrum of bacteria in agar-plate diffusion assays. Studies in vitro indicate that the antibiotic inhibits prokaryotic protein synthesis but not eukaryotic protein synthesis. Cell survival studies performed with strains of Escherichia coli indicate that the antibiotic is a bacteriostatic agent.
\end{abstract}

In the course of screening for novel antibiotics that inhibit protein synthesis initiation, a novel polyene antibacterial agent, bacillaene, was discovered as a component of the fermentation broth of Bacillus subtilis. In addition to this novel compound, the fermentation broth contained at least two other antibiotics, namely the previously described compounds, difficidin and oxydifficidin $^{1 \sim 3)}$. Bacillaene is a hexaene, as shown by its UV absorption spectrum. In in vitro agar diffusion assays, bacillaene inhibits both Gram-positive and Gramnegative bacteria but no inhibitory activity was found against Candida species. The activity in vitro was especially potent against hyper-permeable strains of Escherichia coli. Studies in vitro indicate that the antibiotic is bacteriostatic and that it acts at the level of protein synthesis. The activity is selective in that it inhibits prokaryotic but not eukaryotic protein synthesis.

\section{Isolation of the Organism}

The bacillaene producing organism was isolated from a soil sample collected in Tokyo, Japan. Approximately $0.5 \mathrm{~g}$ of the soil was suspended in $10 \mathrm{ml}$ of sterile phosphate-buffered saline containing $0.1 \%$ gelatin. Aliquots of the suspension were plated on to the surface of nutrient agar composed of the following: yeast extract $2.5 \mathrm{~g}$, peptone $2.0 \mathrm{~g}$, glucose $2.0 \mathrm{~g}$, beef extract $5.0 \mathrm{~g}, \mathrm{MgSO}_{4} \cdot 7 \mathrm{H}_{2} \mathrm{O} 0.5 \mathrm{~g}, \mathrm{FeSO}_{4} \cdot 7 \mathrm{H}_{2} \mathrm{O} 0.2 \mathrm{~g}$, $\mathrm{NaCl} 0.1 \mathrm{~g}$, agar $20.0 \mathrm{~g}$ and distilled water to 1 liter. After autoclaving; filter-sterilized solutions of cycloheximide and colistin were added to the medium so that their final concentrations in the agar were $100 \mathrm{mg}$ and $10 \mathrm{mg}$ per liter of agar, respectively. The plates were incubated for 5 days at $22^{\circ} \mathrm{C}$, at which time colonies exhibiting the morphological and cultural characteristics described below were picked and sub-cultured. They were maintained on slants of medium composed of the following: glucose $5.0 \mathrm{~g}$, yeast extract $5.0 \mathrm{~g}, \mathrm{MgSO}_{4} \cdot 7 \mathrm{H}_{2} \mathrm{O}$ $0.1 \mathrm{~g}, \mathrm{FeSO}_{4} \cdot 7 \mathrm{H}_{2} \mathrm{O} 0.1 \mathrm{~g}$, agar $17.5 \mathrm{~g}$, soil extract $200 \mathrm{ml}$ and tap water $800 \mathrm{ml}$.

Taxonomic Studies

Taxonomic studies of the bacillaene producing organism were done according to the methodology described by GoRdon et al.$^{4,5)}$. Microscopic examination revealed a spore-forming, Gram-positive bacillus, with rounded ends. The rods are non-vacuolated, occur singly and are motile. The spores, produced under aerobic conditions, are oval to cylindrical and are located predominantly in the central region of the sporangia. The sporangia are not swollen.

Macroscopic examination of the colonies grown on the glucose, yeast extract, soil extract salts medium used 
for the maintenance of the organism showed dull, flat colonies that were round with an irregular edge. No pigmentation was observed on Trypticase-Soy agar.

Studies of the physiological characteristics of the organism found that citrate is utilized, nitrate is reduced to nitrite, starch and gelatin are hydrolyzed and acetylmethylcarbinol is produced (Voges-Proskauer test). Glucose, mannitol, xylose, arabinose, sorbitol and sucrose are utilized oxidatively; rhamnose and melibiose are not. Indole is not produced. The culture failed to grow under anaerobic conditions either on solid medium or in glucose or nitrate broths.

When grown aerobically in broth culture, the growth was in the form of a dull, wrinkled pellicle at the surface of the broth. Growth was observed at $28^{\circ} \mathrm{C}$ and $37^{\circ} \mathrm{C}$ but not at $55^{\circ} \mathrm{C}$.

These characteristics are in agreement with those described for Bacillus subtilis by GoRDon et al. ${ }^{3,4)}$ and establish the identity of the organism as Bacillus subtilis. The strain has been deposited in the American Type Culture Collection with the accession number ATCC 55422.

\section{Fermentation}

Yeast beef agar slants, whose composition was: beef extract $1.5 \mathrm{~g}$, yeast extract $3.0 \mathrm{~g}$, peptone $6.0 \mathrm{~g}, \mathrm{~K}_{2} \mathrm{HPO}_{4}$ $3.68 \mathrm{~g}, \mathrm{KH}_{2} \mathrm{PO}_{4} 1.32 \mathrm{~g}$, distilled water 1 liter, were seeded with B. subtilis ATCC 55422 and incubated 24 to 48 hours at $25^{\circ} \mathrm{C}$. The growth was then washed off the slants and used to inoculate $100 \mathrm{ml}$ of germination medium of the following composition contained in $500 \mathrm{ml}$ Erlenmeyer flasks: toasted nutrisoy flour $15 \mathrm{~g}$, soluble starch $15 \mathrm{~g}$, glucose $50 \mathrm{~g}, \mathrm{CoCl}_{2} \cdot 6 \mathrm{H}_{2} \mathrm{O} 0.005 \mathrm{~g}, \mathrm{CaCO}_{3}$ $10 \mathrm{~g}$, distilled water 1 liter. After 24 to 48 hours incubation, $100 \mathrm{ml}$ aliquots from the germination flasks were used to inoculate 1 liter of fresh germination medium in 2.8 liter Erlenmeyer flasks. The fermentation flasks were incubated 48 hours at $25^{\circ} \mathrm{C}$ on a rotary shaker at which time they were harvested.

\section{Isolation and Purification}

The isolation and purification of bacillaene from 10 liters of shake flask culture was carried out as summarized in Fig. 1. The isolation was monitored initially by TLC/bioautographic means and subsequently by the characteristic UV spectrum of the novel antibiotic. The thin layer chromatographic analysis was done on silical gel plates (Merck) with a solvent mixture of methanol-chloroform, 40:60. Detection of the active components was accomplished by bioautography against a hyper-permeable strain of $E$. coli, SGB888. In this system, bacillaene has a $\mathrm{Rf}$ value of 0.76 ; the triene, difficidin, which served as a reference, had a $R f$ value of 0.18 . Low voltage paper electrophoretic analysis was also performed on the fractions. The electrophoretic analysis was carried at $250 \mathrm{~V}(11 \mathrm{~V} / \mathrm{cm})$ for 1.5 hours in an appropriate aqueous buffer on Whatman 1 paper. The electrophoretic mobility of bacillaene relative to vitamin $\mathrm{B}_{12}(0.0)$ and p-nitrobenzenesulfonate (1.0) was 0.1 in a buffer consisting of $0.05 \mathrm{M}$ sodium carbonate and $0.05 \mathrm{M}$ sodium bicarbonate balanced to $\mathrm{pH} 9.2$ and 0.1 in $0.05 \mathrm{M}$ $\mathrm{K}_{2} \mathrm{HPO}_{4}$ balanced to $\mathrm{pH} 7.0$; there was no mobility in buffers balanced to $\mathrm{pH} 4.5$ or $\mathrm{pH} 2.0$.

The isolation of bacillaene was performed as follows. The $\mathrm{pH}$ of the fermented broth (10 liters) was adjusted to 6.5 with hydrochloric acid. Whole broth extraction was carried out by adding 8 liters of ethyl acetate and

Fig. 1. Isolation and purification procedures for bacillaene.

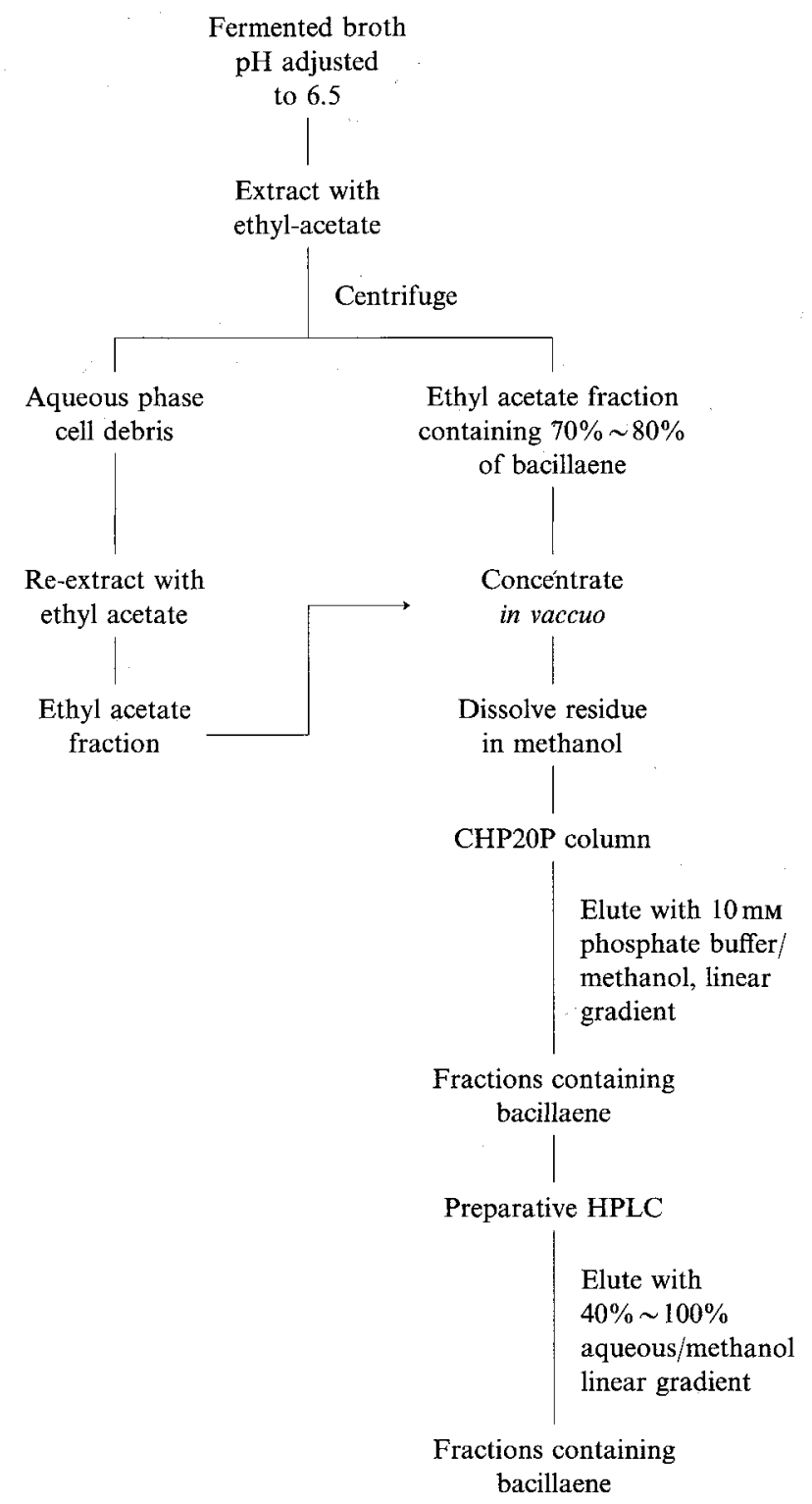


stirring the mixture for thirty minutes. Centrifugation was employed to recover cells, the aqueous and the ethyl acetate layers. The recovered cells and the aqueous phase were combined and extracted in a second step with a fresh portion of 4.0 liters of ethyl acetate. Most of the bacillaene, $c a .70 \%$ to $80 \%$ of the total, was extracted in the first step, as evidenced by UV. spectroscopy of concentrated extracts. The extracts were combined and concentrated in vaccuo to yield an oily residue which was mixed with $5.0 \mathrm{ml}$ of methanol for application to a CHP20P column $(5 \times 30 \mathrm{~cm}$, Mitsubishi Chemical Ind. Ltd. Japan). The column was prepared and equilibrated in $10 \mathrm{~mm}$ phosphate buffer at $\mathrm{pH} 6.5$, and after injection of the sample, a linear gradient was run employing 1.0 liter of starting buffer and 1.0 liter of methanol. At the end of the gradient the elution was continued with pure methanol. A low pressure pump was used to provide a solvent flow rate of $20 \mathrm{ml} /$ minute. Initially, three $500 \mathrm{ml}$ volumes were collected, followed by collecting fractions of $20 \mathrm{ml}$. The $20 \mathrm{ml}$ fractions were checked for the presence of bacillaene by bioautography and UVspectrophometry. Fractions containing bacillaene were pooled and subjected to further purification. Pure bacillaene was obtained from these fractions by preparative HPLC on $\mathrm{C}-18$ reverse phase silica gel $(3 \times 50 \mathrm{~cm}, 10 \mu \mathrm{m}$ spherical; YMC Inc., Wilmington, NC). The column was equilibrated with $40 \%$ methanol in water prior to applying the sample. Elution was effected by a linear gradient from $40 \%$ methanol to $100 \%$ methanol. The flow rate was $50 \mathrm{ml} /$ minute and the detection wavelength was $360 \mathrm{~nm}$. Fractions of $24 \mathrm{ml}$ were collected with the bacillaene eluting in fractions 103 to 107. Fraction 104 was concentrated to give $8 \mathrm{mg}$ of pure bacillaene. In aqueous methanol solution, purified bacillaene was found to be moderately stable when kept at $-20^{\circ} \mathrm{C}$ and protected from light.

\section{Physico-chemical Properties}

Bacillaene was obtained as a white amorphous residue which is soluble in methanol and ethylacetate. The compound is also soluble in chloroform but undergoes rapid decomposition in this solvent.

Bacillaene showed a chemical composition of $\mathrm{C}_{35} \mathrm{H}_{48} \mathrm{O}_{7}$ by high resolution mass spectrometry (VG-ZAB instrument, DTT/DTE/DMSO/glycerol matrix) indicating an unsaturation number of twelve. Measurements were carried out on the $m / z 603$ peak representing the $\mathrm{M}+$ $\mathrm{Na}$ molecular cluster ion in the positive FAB mass spectrum (Fig.2). The measured $m / z$ value for $\mathrm{C}_{35} \mathrm{H}_{48} \mathrm{NaO}_{7}$ was 603.3332 versus a calculated value of 603.3298 . Additional prominent ions in the positive ion $\mathrm{FAB}$ spectrum are $m / z 619(\mathrm{M}+\mathrm{K}), m / z 581(\mathrm{M}+\mathrm{H})$ and $m / z 563$ $(\mathrm{M}+\mathrm{H}-18)$. The negative ion spectrum is dominated by the corresponding $m / z 579(\mathrm{M}-\mathrm{H})$. A lower intensity fragment ion occurs at $m / z 535(\mathrm{M}-\mathrm{H}-44)$ and suggests the loss of $\mathrm{CO}_{2}$, caused by the presence of a carboxyl group in the molecule. Degree of unsaturation and total carbon count of the molecular formula were confirmed by the UV and the ${ }^{13} \mathrm{C}-\mathrm{NMR}$ spectrum. The UV spectrum (diode array, HP 1090LC) shows the char-

Fig. 2. Positive-ion FAB mass spectrum of bacillaene.

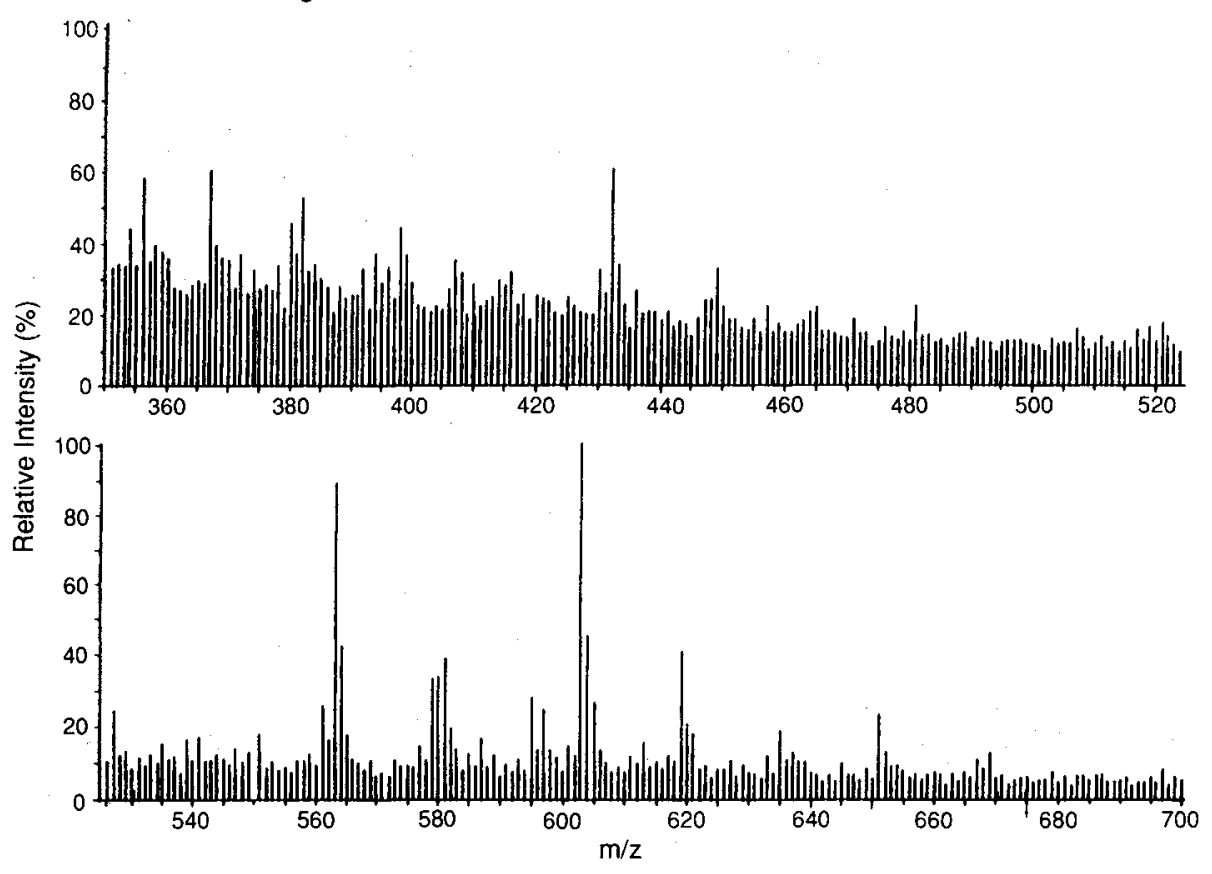


acteristic band pattern of a conjugated hexaene with individual bands appearing at 343,361 and $382 \mathrm{~nm}$ (Fig. 3). The ${ }^{13} \mathrm{C}$-NMR spectrum (Bruker AM-500, $125 \mathrm{MHz}$, methanol- $d_{6}$, Fig. 4) shows 35 signals; three carbonyl, 18 olefinic and 14 tetrahedral carbons. Twelve double bond equivalents result from the observed olefinic and carbonyl resonances. Since the number equals the degree of unsaturation expressed by the molecular formula, no ring structures are present in bacillaene. The molecule is also devoid of symmetry as evidenced by the individual appearance of carbon resonances with the exception of two carbons overlapping at 71.8 , and two others at $128.7 \mathrm{ppm}$. Table 1 summarizes carbon chemical shifts and corresponding signal multiplicities as determined by DEPT experiments. Three carbonyl resonances at 172.0, 178.1 , and $178.6 \mathrm{ppm}$ are likely due to two ester functionalities and one carboxylic acid group, the later also being evident from the negative ion FAB mass spectrum and the lack of electrophoretic mobility of

Fig. 3. UV spectrum of bacillaene.

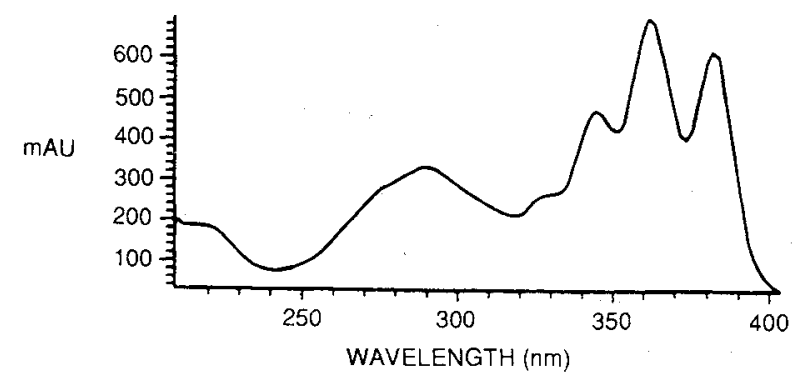

bacillaene at acidic $\mathrm{pH}$. A set of 18 olefinic carbons, two singlets and 16 doublets appears in the shift range from 122.0 to $143.0 \mathrm{ppm}$. With the conjugated hexaene chromophore accounting for twelve carbons, the remaining six signals indicate that three additional double bonds are present in the molecule. The carbon count of the molecular formula is completed by 14 tetrahedral carbons which comprise four methine, three methylene, and seven methyl groups. On the basis of their chemical shift, three methine carbons, one at 67.9 and two overlapping at $71.8 \mathrm{ppm}$, are attached to oxygen atoms. Carbon multiplicities call for a total of 47 nonexchangeable hydrogens, which together with the one exchangeable proton of the carboxylic acid group adds up to the 48 hydrogens, required by the molecular formula. The proton spectrum of bacillaene (Bruker AM- $500,500 \mathrm{MHz}$, methanol- $d_{6}$ ) is in agreement with the above analysis and is shown in Figure 5.

\section{Biological Activity}

\section{Anti-bacterial Activity In Vitro}

The anti-bacterial activity in vitro of bacillaene was determined against a wide spectrum of bacteria using agar plate diffusion assays ${ }^{8}$. Briefly, the organisms were seeded in Luria agar (Bacto-tryptone $10 \mathrm{~g}$, yeast-extract $5.0 \mathrm{~g}, \mathrm{NaCl} 10 \mathrm{~g}$, water 1 liter) and the test compounds were loaded into $3 \mathrm{~mm}$ wells punched in the agar. The plates were incubated at $37^{\circ} \mathrm{C}$ over-night and the zones of growth inhibition measured. The growth inhibition zone sizes are as shown in Table 2. Bacillaene has no activity against Saccharomyces cerevisiae or Candida

Fig. 4. ${ }^{13} \mathrm{C}$ NMR spectrum of bacillaene (125 MHz, methanol- $\left.d_{6}\right)$.

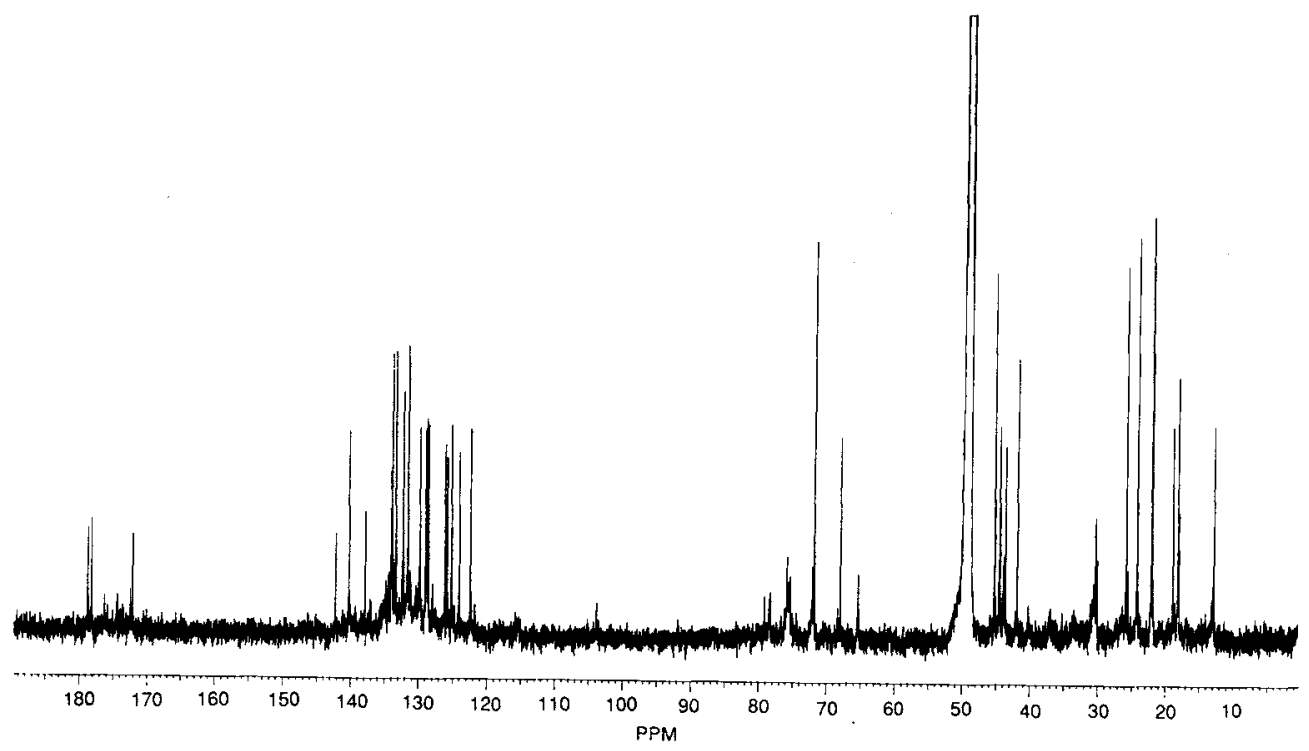


Table $1 .{ }^{13} \mathrm{C}$ NMR data for bacillane.

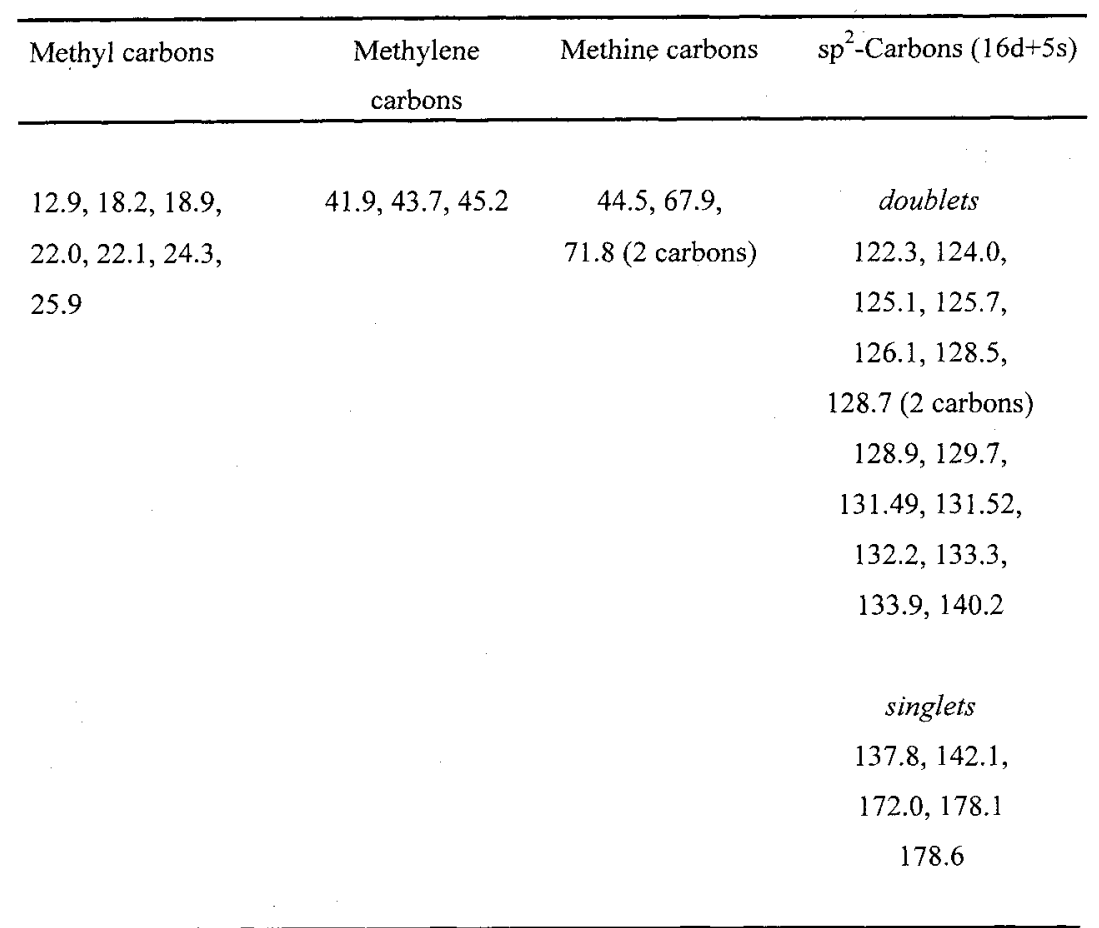

The spectrum was recorded in methanol- $d_{6}$, chemical shifts are given in ppm.

Fig. 5. ${ }^{1} \mathrm{H}$ NMR spectrum of bacillaene $\left(500 \mathrm{MHz}\right.$, methanol- $\left.d_{6}\right)$.

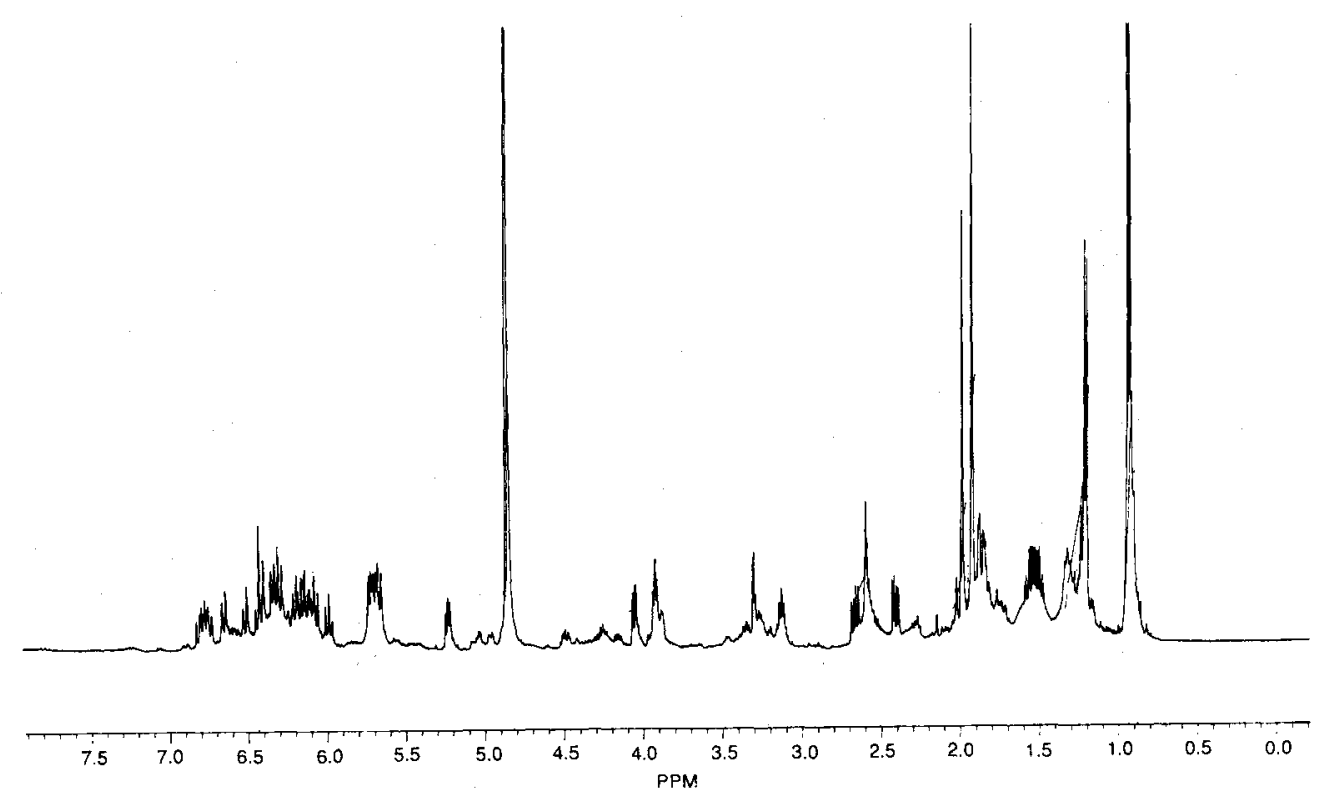

albicans. The minimum inhibitory concentration value of bacillaene against wild type $E$. coli and hyper permeable strains of $E$. coli $^{5,6)}$ were determined by employing a standard two-fold tube dilution assay". Bacillaene is extremely potent against hyper-permeable strains of $E$. coli with an MIC of less than $1.0 \mu \mathrm{g} / \mathrm{ml}$ in all cases except against the E. coli strain SC10857 where the MIC is $5.0 \mu \mathrm{g} / \mathrm{ml}$. The results of a typical MIC study is as shown in Table 3. 


\section{Inhibition of Protein Synthesis In Vitro}

To determine the biological mode of action of bacillaene, in vitro protein synthesis assays were performed in the presence of the compound. The procaryotic protein synthesis assay employed was an $E$. coli based transcription-translation coupled assay ${ }^{10)}$, whereas, the eucaryotic protein synthesis assay was a rabbit-reticulocyte based system ${ }^{1,12)}$. In both systems,

Table 2. Anti-microbial spectrum of bacillaene as determined using agar plate diffusion assays.

\begin{tabular}{lc}
\hline Organism & Zone size in mm \\
\hline Escherichia coli SC10909* & 20 \\
E. coli BAS847 & 18 \\
E. coli K10 & 8 \\
Klebsiella pneumoniae SC10440 & 9 \\
K. pneumoniae SC9527 & 8 \\
Proteus vulgaris SC9416 & 22 \\
Serratia marcescens SC9783 & 24 \\
Bacillus thuringiensis SC2928 & 16 \\
Staphylococcus aureus SC2400 & 12 (hazy) \\
S. aureus $209 \mathrm{P}$ & 12 (hazy) \\
S. epidermidis SC9087 & 0 \\
Pseudomonas aeruginosa SC8723 & 0 \\
Saccharomyces cerevisiae SC1600 & 0 \\
Candida albicans SC5314 & 0 \\
\hline
\end{tabular}

* These strains are hyperpermeable.

Table 3. MIC values of bacillaene against selected strains of Escherichia coli.

\begin{tabular}{lc}
\hline Organism & $\mathrm{MIC}(\mu \mathrm{g} / \mathrm{mL})$ \\
\hline Escherichia coli $\mathrm{K} 10$ & 37.0 \\
E. coli $\mathrm{SC} 10909^{*}$ & 0.09 \\
E. coli $\mathrm{SC} 10857^{*}$ & 5.0 \\
E. coli $\mathrm{SC} 10896^{*}$ & 0.6 \\
E. coli $\mathrm{BAS} 2006^{*}$ & 0.6 \\
E. coli BAS $847^{*}$ & 0.5 \\
\hline
\end{tabular}

* These strains are hyperpermeable. the incorporation of ${ }^{35} \mathrm{~S}$-labelled methionine into acid-insoluble material was monitored. Bacillaene was found to inhibit prokaryotic in vitro protein synthesis, however, it failed to inhibit eucaryotic protein synthesis at the concentrations tested. At a final concentration of $0.75 \mu \mathrm{g} / \mathrm{ml}$, bacillaene inhibited $>85 \%$ of incorporation of the radio-labelled amino acid into acid-insoluble material in the procaryotic protein synthesis assay as compared to the control where no inhibitor was added to the assay mix. The inhibition was $95 \%$ when the concentration of bacillaene was increased to $1.5 \mu \mathrm{g} / \mathrm{ml}$. No inhibition of the incorporation of the radio-labelled methionine into acid-insoluble material was seen at similar concentrations in the in vitro eucaryotic protein synthesis assay. The results are as shown in Table 4.

\section{Effect of Bacillaene on Cell Viability}

To study the effect of bacillaene on cell viability, standard broth dilution assays in the presence of the drug were performed $^{9)}$. Briefly, the drug was added at $10 \times$ the MIC to a $\log$ phase culture of $E$. coli strain BAS- 847 . The culture was grown aerobically in Luria broth at $37^{\circ} \mathrm{C}$. At various time intervals, aliquots of the culture were withdrawn, diluted and plated on Luria agar. The plates were incubated at $37^{\circ} \mathrm{C}$ over-night and the number of survivors determined by counting the colonies. As is the case for many protein synthesis inhibitors, the growth inhibitory activity of bacillaene appears to be bacteriostatic $^{9)}$.

\section{Discussion}

This report is the first, to our knowledge, of an antibacterial antibiotic from the genus Bacillus with a UV spectrum of a conjugated hexaene. Conjugated polyene antibacterial antibiotics have been reported previously from members of this genus, e.g., difficidin and oxydifficidin, proticin and aurantinin ${ }^{1 \sim 3,13 \sim 16}$. However, all these have been classified as trienes. Moreover, they all contain ring structures whereas bacillaene is unique in this group in that it does not.

Table 4. In vitro protein synthesis inhibition assay.

\begin{tabular}{lccc}
\hline Compound & $\begin{array}{c}\text { concentration } \\
{[\mu \mathrm{g} / \mathrm{mL}]}\end{array}$ & $\begin{array}{c}\text { \% of control } \\
\text { Procaryotic } \\
\text { system }\end{array}$ & $\begin{array}{c}\text { \% of control } \\
\text { Rabbit Reticulocyte } \\
\text { system }\end{array}$ \\
\hline Chloramphenicol & 4.0 & 5.0 & 92 \\
Bacillaene & 0.75 & 12.0 & 93 \\
Bacillaene & 1.5 & 5.0 & 93 \\
Cycloheximide & 5.0 & 94 & 8.0 \\
\hline
\end{tabular}


Another open chain polyene, a conjugated pentaene, enacyloxin, produced by a bacterium, Gluconobacter sp., has been described ${ }^{17)}$. The fact that Bacillus subtilis ATCC 55422 is capable of co-producing both the open and closed types of polyenes is of interest. Our studies strongly suggest that bacillaene does not cross the outer cell-membrane easily in as much as it has superior activity versus bacteria that are hyper-permeable due to a defect in the composition of the outer cell-membrane as compared to those that are not. The reason for this may become clear when the structure of bacillaene is fully elucidated.

Bacillaene, like difficidin and oxydifficidin and enacyloxin inhibits protein synthesis. All of these compounds are selective in their mode of action in that they inhibit prokaryotic but not eukaryotic protein synthesis. Some of our unpublished data suggest that bacillaene acts at the level of initiation of protein synthesis. Further studies are in progress to elucidate more difinitivley the exact mechanism by which bacillaene inhibits procaryotic protein synthesis.

\section{References}

1) Zimmerman, S. B.; C. D. Schwartz, R. L. Monaghan, B. A. Pelak, B. Weissberger, E. C. Gilfillan, S. Mochales, S. Hernandez, S. A. Currie, E. Tejera \& E. O. Stapley: Difficidin and oxydifficidin: Novel broad spectrum antibacterial antibiotics produced by Bacillus subtilis. I. Production, taxonomy and antibacterial activity. J. Antibiotics 40: 1677 1681, 1987

2) Wilson, K. E.; J. E. Flor, R. E. Schwartz, H. Joshua, J. L. Smith, B. A. PelaK, J. M. Leisch \& O. D. Hensens: Difficidin and oxydifficidin: Novel broad spectrum antibacterial antibiotics produced by Bacillus subtilis. II. Isolation and physico-chemical characterization. J. Antibiotics 40: 1682 1691, 1987

3) ZweERINK, M. M. \& A. EdISON: Difficidin and oxydifficidin: Novel broad spectrum antibacterial antibiotics produced by Bacillus subtilis. III. Mode of action of Difficidin. J. Antibiotics 40: 1692 1697, 1987

4) Buchanan, R. E. \& N. E. Gibbons $(E d$.): Bergey's manual of determinative bacteriology. 8th $E d$. Williams and Wilkins Co., Baltimore, 1974

5) Gordon, R. E.; W. C. Haynes \& C. H. Pang (Ed.): Genus Bacillus. In Agricultural Monograph handbook No. 427. Agricultural Research Services, USDA, Washington D.
C. 1973

6) SAMPSON, B. A. \& S. A. Benson: Escherichia coli strains with defined mutations which alter cellular permeability. J. of Indust. Microbiol. 1: 335 340, 1987

7) Sampson, B. A.; R. Misra \& S. A. Benson: Identification and characterization of a new gene of Escherichia coli $\mathrm{K}-12$ involved in outer membrane permeability. Genetics 122: $491 \sim 501,1989$

8) Cleeland, R. \& E. Grunberg: Laboratory evaluation of new antibiotics in vitro and in experimental animal infections. In Antibiotics in laboratory medicine. Ed., V. LORAIN, pp. 506 548, Williams and Wilkins, Baltimore, 1980

9) Thrupp, L. D.: Chapter 4. Susceptibilty testing of antibiotics in liquid media. In Antibiotics in laboratory medicine. Ed., V. LoRIAN, pp. $73 \sim 113$, Williams and Wilkins, Baltimore, 1980

10) Modolell, J.: The S-30 system from Escherichia coli. Methos Mol. Biol. 1: 1 65, 1971

11) KozAK, M.: Evaluation of the fidelity of initiation of translation in reticulocyte lysates from commercial sources. Nucl. Acids Res. 18: 2828, 1990

12) Jackson, R. \& T. Hunt: Preparation and use of nuclease-treated rabbit reticulocyte lysates for the translation of eukaryotic messenger RNA. In Meth. Enzymol. Ed., S. FleisCher \& B. FLEISCHER, 96: 50 73, 1983

13) Konda, Y.; A. Nakagawa, Y. Harigaya, M. Onda, R. Masuma, S. OMMURA: Aurantinin B, a new antimicrobial antibiotic from bacterial origin. J. Antibiotics 41: $268 \sim 270,1988$

14) Nishikiori, T.; R. Masuma, R. Oiwa, M. Katagiri, J. AWAYA, Y. IWAI \& S. ŌMURA: Aurantinin, a new antibiotic of bacterial origin. J. Antibiotics 31: $525 \sim 532$, 1978

15) Watanabe, T.; T. SuzUKI \& K. IzaKI: New polyenic antibiotics active against Gram-positive and Gramnegative bacteria. V. Mode of action of enacyloxin Iia. J. Antibiotics 44: $1457 \sim 1459,1991$

16) Watanabe, T.; N. Okubo, T. Suzuki \& K. Izaki: New polyenic antibiotics active against Gram-positive and Gram-negative bacteria. VI. Non-lactonic polyene antibiotic, enacyloxin Iia, inhibits binding of aminoacyltRNA to A site of ribosomes. J. Antibiotics 45: 572 577, 1992

17) Prave, P.; D. Sukatsch \& L. Vertesy: Proticin, a new phosphorous-containing antibiotic. I. Taxonomy, fermentation, isolation and biological properties. J. Antibiotics 25: $1 \sim 3,1972$ 